Deikalo I. M., Osadchuk D. V., Karel O. I., Handzhalas M. B. Minimally-invasive technologies in the treatment of choledocholithiasis complicated by biliary pancreatitis. Journal of Education, Health and Sport. 2021;11(03): 294-309. eISSN 2391-8306. DOI http://dx.doi.org/10.12775/JEHS.2021.11.03.028

https://apcz.umk.pl/czasopisma/index.php/JEHS/article/view/JEHS.2021.11.03.028

https://zenodo.org/record/5559802

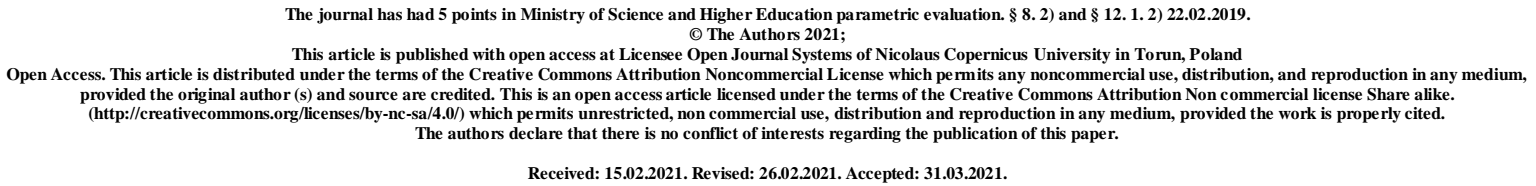

UDK 616.37-002-06:616.367-003.7-089.819

\title{
MINIMALLY-INVASIVE TECHNOLOGIES IN THE TREATMENT OF CHOLEDOCHOLITHIASIS COMPLICATED BY BILIARY PANCREATITIS
}

\author{
I. M. Deikalo, D. V. Osadchuk, O. I. Karel, M. B. Handzhalas
}

\section{The National Higher education institution «I. Horbachevsky Ternopil National Medical University of the Ministry of Health of Ukraine», Ternopil, Ukraine}

\begin{abstract}
Deikalo Ihor Mykolaiovych - Honored Doctor of Ukraine, Doctor of Medicine, Professor of Surgery, Head of the Department of General Surgery of I. Horbachevsky Ternopil National Medical University. Tel. 0672578296.

Osadchuk Dmytro Vasyliovych - Candidate of Medical Sciences, Associate Professor of the Department of General Surgery of I. Horbachevsky Ternopil National Medical University, Head of the Department of Surgery of Ternopil City Municipal Emergency Hospital. Tel. 0672086943.

Karel Oleh Ihorovych - Surgeon of Ternopil City Municipal Emergency Hospital. Tel. 09758928 32, kareloi@ukr.net

Handzhalas Mykola Bohdanovych - Surgeon of Ternopil City Municipal Emergency Hospital.Tel. 096 9958931
\end{abstract}

\section{Abstract}

Minimal invasive endoscopic technologies are used in the treatment of patients with biliary pancreatitis with complicated cholangitis and biliary sepsis. 56 patients were treated for the period $2014-2018$, aged $65.5 \pm 15.18$ years. ERCP was performed in $31(55,3 \%)$ patients, in $13(23,2 \%)$ - surgical intervention was performed without contrast of extrahepatic bile ducts. Papillotomy in 52 cases $(96,4 \%)$ was performed by string papilloma and in 4 $(7,1 \%)$ - by needle. In all cases, subtotal papilloprotectomy was performed [1], supplemented by balloon sphincteroplasty. In the I group, the patients included patients with biliary 
pancreatitis clinic, in group II patients with clinic of biliary sepsis, in the III group patients with purulent cholangitis clinic, biliary sepsis and septic shock. In the 1st and 2nd groups of patients, mortality was not observed. In the 3rd group, 3 patients died $(37,5 \%)$. The rest of the patients are discharged from the hospital in a satisfactory condition. A decrease in the level of markers of hepatitis cytolysis (AlAT, AsAT, GGTP, L-FABP) was observed during surgical procedures without ERCP, indicating the toxic effect of contrast on the liver parenchyma. LFABP is a highly informative marker for hepatocyte cytolysis and can be used as a criterion for hepatic insufficiency and prognosis of biliary sepsis. The high efficiency of transpacillary endoscopic surgical techniques in the treatment of biliary pancreatitis and biliary sepsis was noted.

Keywords: biliary pancreatitis; cholecholithiasis; biliary sepsis; septic shock; endoscopic retrograde pancreatic cholangiography; endoscopic papillomotorotomy.

Introduction. Acute biliary pancreatitis should be considered a combination of acute pancreatitis with chronic or acute diseases of the biliary tract. The latter is a broad concept that unites all pathological conditions of the biliary tract, including without inflammation of the gallbladder (choledocholithiasis, stenosis of the distal choledochus, stenosis or wedged concretion of the major duodenal papilla, functional dyskinetic disorders of the extrahepatic bile ducts) 3.6].

According to various authors, the frequency of biliary pancreatitis on the background of choledocholithiasis ranges from 25 to $65.3 \%$. According to the VI World Congress of Gastroenterologists, $10 \%$ of the world's population suffers from housing and communal services. Every decade the number of patients increases approximately 2 times. Women get sick 2-3 times more often than men. With age, the incidence increases. However, in recent years in Europe and North America there has been a tendency to reduce the incidence of biliary pancreatitis due to earlier diagnosis and surgical interventions for chronic calculous cholecystitis [1].

Diagnosis and treatment of combined lesions of the biliary system and pancreas - one of the biggest problems of abdominal surgery [2]. The proportion of patients with acute biliary pancreatitis in the hospitals of abdominal surgery is from 15 to $25 \%$. In almost $85 \%$ of cases, biliary pancreatitis is a complication of cholelithiasis, and in $15 \%$ there are secondary enzymatic cholecystitis $[2,4,12,13]$.

Problems of treatment of acute biliary pancreatitis (ABP) are caused by the potential occurrence of a cascade of combined pathological processes in the pancreatobiliary zone, the 
development of destructive forms of pancreatic lesions with necrosis in the retroperitoneal adipose tissue (parapancoligitis, parapancreatitis, parapancreatitis, , 11]. All this creates a basis for contradictions in the treatment and tactical approaches to the treatment of ABP and the timing and scope of surgical interventions [2, 3, 4, 6 - 11, 14, 15].

Materials and methods: The work presents materials of clinical observation, laboratory and instrumental methods of studying the functional state of hepatocytes in 63 patients with biliary pancreatitis due to gallstone disease.

At the prehospital and hospital stages, patients underwent the following laboratory and instrumental methods of examination: general blood test (Erba Mannheim Elite 3), general urine test (microscopy), diastasuria and amylase level (SpineLab scientific and AlphaECG600G kit), biochemical blood test (LabLine - 70), coagulogram (LabLine - 70), blood group and rhesus affiliation (according to the AB0 system by the coliclone method). All patients underwent ultrasound of the abdominal cavity (ESAOTE MY LAB 7). Spiral CT of the abdominal cavity with prenatal amplification (Siemens Somatom Emotion, 16-slice) was performed in $16(25.3 \%)$ patients and magnetic resonance cholangiography was performed in $1(1.58 \%))$ by the apparatus (Siemens Magnetom Avanto $1.5 \mathrm{~T}$ ).

The following markers were used to study the cytolytic syndrome of hepatocytes: alanine aminotransferase (ALT), reference values for men up to 40, for women up to $32 \mathrm{U} / 1$.; aspartate aminotransferase (AST), reference values for men up to 38 , for women up to 31 U/l.; gamma-glutamyl transpeptidase (GGTP) by kinetic analysis, Master "T" apparatus, reference values for men 11 - 50, for women 9 - $32 \mathrm{U} / \mathrm{l}$; and the modern marker L-type fatty acid-binding protein (L-FABP) by enzyme-linked immunosorbent assay, the apparatus Multiscan FC, the reference values of which are up to $20 \mathrm{ng} / \mathrm{ml}$.

Total blood bilirubin, urinary diastase, ALT, AST, GGTP and L-FABP were monitored at 18 and 42 hours of postoperative period.

In the general analysis of blood leukocytosis was from 10.3 to $14.2 \times 10^{9} / 1$, the average value was $11.8 \times 10^{9} /$, and the shift of the leukocyte formula to the left, the level of rodshaped neutrophils ranged from $8 \%$ to $21 \%$, on average $11.7 \%$ were noted,. In the general analysis of urine in all patients significant deviations were not noted.

All patients underwent intensive infusion therapy aimed at accumulating the phenomena of pancreatogenic shock, hemodynamic disorders and for preoperative preparation, lasting from 2 to 26.1 hours, an average of 6.1 hours. For this purpose, we prescribe the following groups of drugs: antispasmodics, proton pump inhibitors, protease inhibitors, nonsteroidal anti-inflammatory drugs, broad-spectrum antibiotics (cephalosporins 
of the III-IV generation), rheological blood substitutes, starches, colloids, crystalloids. Premedication included a standard set of drugs: belladonna alkaloids, antihistamines, anxiolytics. Surgery was performed under ataranalgesia with anxiolytics (sibazon), ketamine, propofol.

Results of the surveys and discussion of the results: All 63 patients were divided into two groups: the first (I) - $33(52.38 \%)$ patients who were treated by conventional methods, which included preoperative preparation, ataranalgesia, ERCP, LE.

Second group (II) - $30(47.62 \%)$ patients treated with a method that included preoperative preparation, ataranalgesia, EPST, LE, endobiliary stenting of hepaticocholedochus with a polypropylene stent, 10 Fr $80 \mathrm{~mm}$ long. So, ERCP was not performed in the patients of the second group.

As patients in group I were treated by conventional methods, it was considered to be a control group.

The I group, patients with gallstone disease complicated by choledocholithiasis and biliary pancreatitis, who were treated by traditional methods using ERCP, EPST,

\section{LE and stenting of the extrahepatic bile ducts.}

30 patients were selected for this group, including 18 women (60\%) and 12 men, which was $40 \%$. The age of patients in this group ranged from 21 to 49 years, the average age was 35.5 , which indicates that people who has this disease are mostly of working age. The duration of the period of jaundice until hospitalization in a specialized hospital ranged from 1 to 6 days, an average of 2.7 days. Periods of diagnostic search at the outpatient and hospital stages are not taken into account. Body temperature ranged from 36.4 to $38.0{ }^{0} \mathrm{C}$., the average value is $37.0{ }^{\circ} \mathrm{C}$. Among patients in this group, 11 (36.6\%) were diagnosed with anamnesis of gallstone disease and 19 (63.4\%) were diagnosed for the first time. Nausea was observed in $30(100.0 \%)$ patients, and vomiting in 27 (90.0\%). In 27 (90.0\%) patients of this subgroup, dark brown urine and hypo-, acholic feces were noted in 21 (70.0\%). Heart rate (HR) ranged from 64 to 110 beats per minute, with a mean of 82.2. Tachycardia was noted in 8 patients, which is $26.6 \%$.

The surgery was performed in the Sims' position - intermediate between the supine position and the one on the left side, using an Olympus video endoscopic rack and X-ray $\mathrm{C}$ arch Mobile X-Ray system IMAX 112C Scientific. In the case of a concrete wedge in the opening of major duodenal papilla, 26 patients $(86.7 \%)$ underwent needle papillotomy and lithoextraction for the first time. At the next stage, selective cannulation of hepaticocholedochus was performed using a 0.25 guide with a hydrophilic flexible X-ray 
contrast tip. After receiving the so-called "working intersection" of the instruments (Figure 1), an aspiration test was performed, upon receiving of bile, ERCP was performed with 5\% triombrast solution, then supplemented, when necessary, papillosphincterotomy with string papillotome. Upon the guide left, the instrument was changed from a papillotome to a lithoextractor balloon. Hepaticocholedochus revision and lithoextraction were performed with the balloon of $10-15 \mathrm{~mm}$ in diameter. The stenting of bile ducts with a polypropylene stent 8 Fr, $8 \mathrm{~cm}$ long was performed. The operation lasted from 31 to 65 minutes.

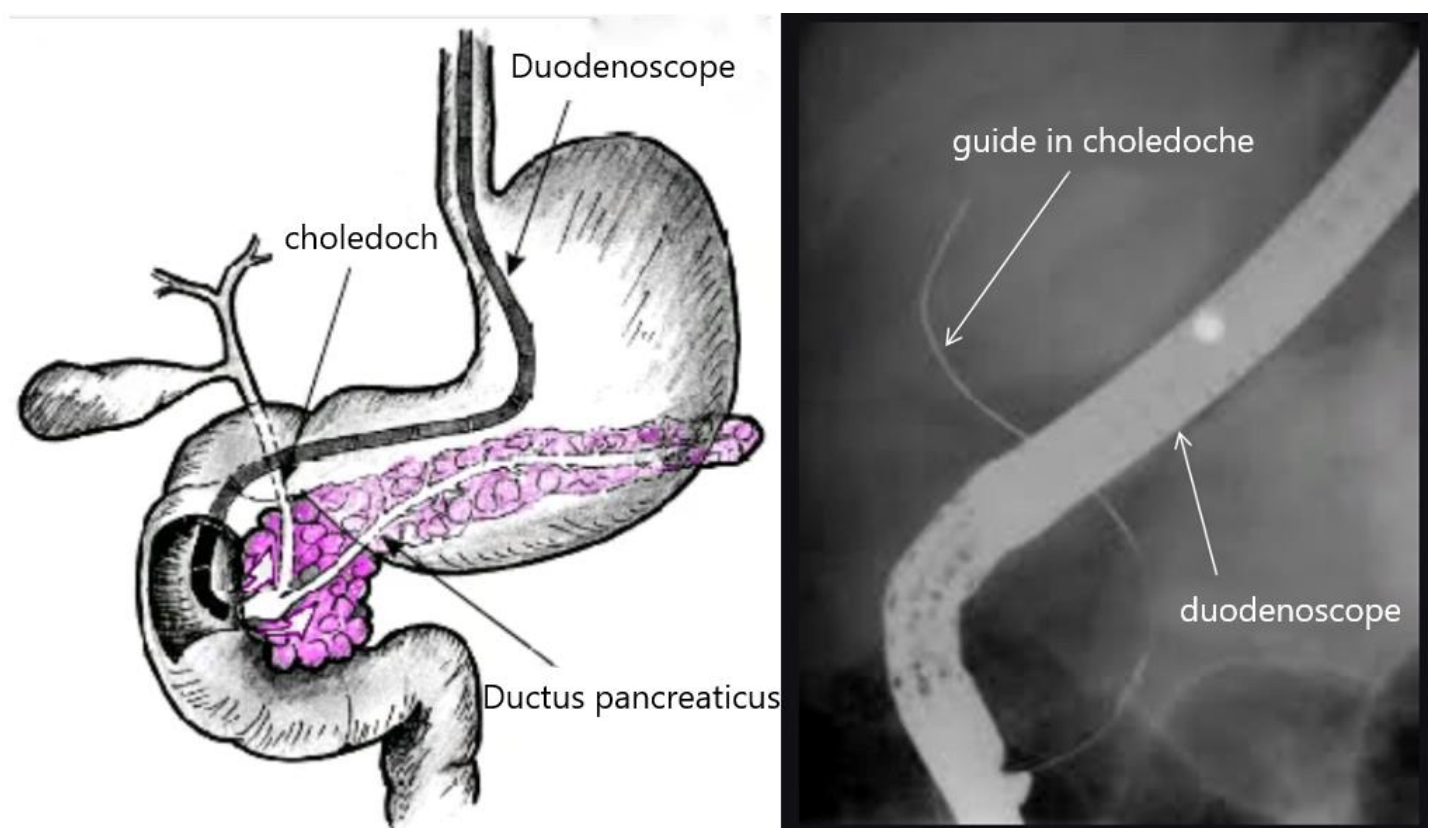

Figure 1. Working intersection

Group II, patients with gallstone disease complicated by choledocholithiasis and biliary pancreatitis, who underwent EPST, LE and stenting of the extrahepatic bile ducts. 33 patients were selected for this group, including 22 women (66.7\%) and 11 men, which was $33.3 \%$. The age of patients in this group ranged from 19 to 50 years, the average age was 35.8 , that means that mostly people of working age have this disease. The duration of the jaundice period before hospitalization in a specialized hospital ranged from 1 to 7 days, an average of 3.0 days. Periods of diagnostic search at the outpatient and hospital stages are not taken into account. Body temperature ranged from 36.5 to $38.2^{0} \mathrm{C}$., The average value is $37.1^{\circ} \mathrm{C}$. Among the patients of this group, 10 (30.3\%) were diagnosed with a gallstone disease in the anamnesis and 23 (69.7\%) were diagnosed for the first time. Nausea was observed in 33 (100.0\%) patients, and vomiting in 29 (87.9\%). In 29 patients (87.9\%) of this subgroup, dark brown urine was noted and hypo-, acholic feces were noted in $22(66.7 \%)$. Heart rate (HR) ranged from 65 to 115 beats per minute, with a mean of 84.3. Tachycardia was noted in 9 patients, which is $27.3 \%$. 
The surgery was performed in the Sims' position - intermediate between the supine position and the one on the left side, using an Olympus video endoscopic rack and $\mathrm{X}$-ray $\mathrm{C}$ arch Mobile X-Ray system IMAX 112C Scientific. In the case of a concrete wedge in the opening of major duodenal papilla, 26 patients $(86.7 \%)$ underwent needle papillotomy and lithoextraction for the first time. At the next stage, selective cannulation of hepaticocholedochus was performed using a 0.25 guide with a hydrophilic flexible X-ray contrast tip. After receiving the so-called "working intersection" of the instruments, an aspiration test was performed, upon receiving bile it was being supplemented, when necessary, papillosphincterotomy with string papillotome was also carried out. Upon the guide left, stenting of extrahepatic bile ducts with a polypropylene stent $8 \mathrm{Fr}, 8 \mathrm{~cm}$ long was performed. The operation lasted from 16 to 37 minutes.

Dynamics of indicators of hepatodepressive syndrome. As can be seen in table 1, at the time of admission to the hospital in groups of examined patients, the activity of GGTP and total bilirubin were almost the same $(\mathrm{p}>0.05)$.

In the patients who underwent contrast cholangiography, the activity of serum did not change statistically significantly compared with the value at admission $(p<0.05)$. and compared with 18 and 42 hours of observation $\left(\mathrm{p}_{2}>0.05\right)$, although a tendency of its increase to 42 hours was noted.

Table 1 - Features of hepatodepressive syndrome in patients with acute pancreatitis who underwent contrast cholangiography $(\mathrm{M} \pm \mathrm{m})$

\begin{tabular}{|c|c|c|c|}
\hline Period & With contrast $(n=30)$ & $\begin{array}{l}\text { Without contrast } \\
(\mathrm{n}=29)\end{array}$ & $\mathrm{p}_{1}$ \\
\hline \multicolumn{4}{|l|}{ GGTP, $\mathrm{U} \cdot 1^{-1}$} \\
\hline Before surgery & $579,5 \pm 64,1$ & $479,7 \pm 44,9$ & $>0,05$ \\
\hline $18 \mathrm{~h}$ & $643,8 \pm 66,6$ & $420,0 \pm 43,5$ & $<0,05$ \\
\hline $42 \mathrm{~h}$ & $618,9 \pm 61,7$ & $369,50 \pm 43,2$ & $<0,05$ \\
\hline $\mathrm{p}_{2}$ & $>0,05$ & $>0,05$ & \\
\hline \multicolumn{4}{|c|}{ Total bilirubin, $\mathrm{mmol} \cdot \mathrm{l}^{-1}$} \\
\hline Before surgery & $208,6 \pm 13,8$ & $204,0 \pm 14,5$ & $>0,05$ \\
\hline $18 \mathrm{~h}$ & $229,0 \pm 14,5$ & $149,1 \pm 12,6^{*}$ & $<0,05$ \\
\hline $42 \mathrm{~h}$ & $187,3 \pm 13,5$ & $103,4 \pm 10,4^{*}$ & $<0,05$ \\
\hline $\mathrm{p}_{2}$ & $<0,05$ & $<0,05$ & \\
\hline
\end{tabular}

Notes. Here and in other tables:

$1 *$ - differences in data before surgery are statistically significant $(\mathrm{p}<0,05)$.

2. $\mathrm{p}_{1}$ - difference in groups of patients who used contrast.

3. $\mathrm{p}_{2}$ - differences in relation to 18 and 42 hours of the postoperative period. 
At the same time, in patients without contrast cholangiography, the activity of serum did not change statistically significantly compared with the value at admission $(\mathrm{p}<0.05)$. and compared with $18\left(\mathrm{p}_{2}>0.05\right)$, although a tendency of the decrease of the studied indicator was noted. Due to this, after 18 and 42 hours of treatment, the serum GGTP activity of patients without cholangiography was statistically significantly lower than in patients who underwent cholangiography ( 34.8 and $40.3 \%, \mathrm{p}_{1}<0.05$, accordingly).

Despite the absence of statistically significant differences in the dynamics of absolute values of GGTP activity in serum in groups of examined patients, its average ratio of individual values to the average value of the preoperative period (Fig. 2) after $42 \mathrm{~h}$ in patients without contrast cholangiography was significantly lower $(28.0 \%, \mathrm{p}<0.05)$.

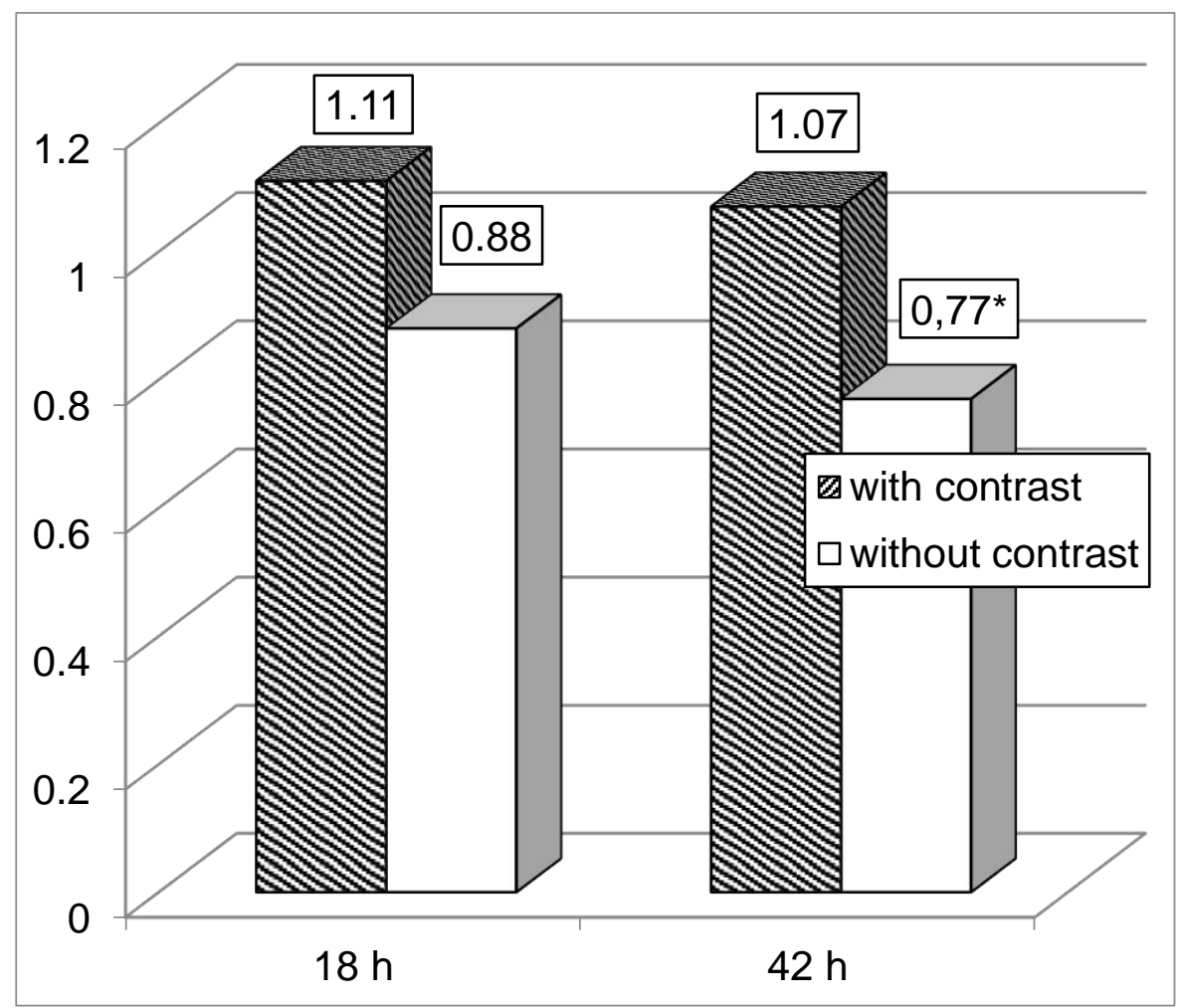

Figure 2 - Dynamics of the average ratio of individual values of serum GGTP activity to the average value of the preoperative period in patients with acute cholangitis who underwent contrast cholangiography

The obtained result indicates the statistical significance of the degree of reduction of serum GGTP activity during treatment in the group of patients without contrast cholangiography, compared with patients who underwent this procedure. 
In turn, the content of total bilirubin in the group of patients who underwent contrast cholangiography (see Table 1), up to 18 hours of observation increased, which was statistically insignificant ( $>>0.05$ ), and then it decreased, up to 48 hours reaching level $(187.3 \pm 13.5) \mathrm{mmol} \cdot \mathrm{l}^{-1}$. The obtained result was significantly less than after $18 \mathrm{~h}$ (by $18.2 \%$, $\left.\mathrm{p}_{2}<0.05\right)$.

However, in the group of patients who did not perform contrast cholangiography, the content of total bilirubin in the serum decreased. Compared with the initial state, the indicator after $18 \mathrm{~h}$ became lower by $26.9 \%(\mathrm{p}<0.05)$, after $42 \mathrm{~h}$ it decreased by $49.3 \%(\mathrm{p}<0.05)$. In this period, the content of total bilirubin in the blood serum was also lower and compared with 18 h of observation (by $30.6 \%, \mathrm{p}_{2}<0.05$ ).

This dynamics of the studied indicator in the comparison groups led to the fact that after 18 and 42 hours of observation, the serum content of total bilirubin in patients without contrast cholangiography was statistically significantly lower than in patients who underwent this procedure (accordingly by 34.9 and $44,8 \%, \mathrm{p}<0.05$ ).

Analysis of the dynamics of the average ratio of individual values of total serum bilirubin to the average value of the preoperative period showed (Fig. 3) that after $18 \mathrm{~h}$ and 42 $\mathrm{h}$ after observation in patients who did not undergo contrast cholangiography, the rate was statistically significantly lower (respectively by 35.4 and $46.3 \%, \mathrm{p}<0.05$ ), which indicates a significantly greater degree of decrease in the value of the studied indicator in the group of patients without contrast cholangiography.

Thus, regardless of the implementation of contrast cholangiography, the activity of GGTP in the serum in the postoperative period in the observation groups does not change significantly compared with the level at hospitalization. The tendency to increase of the value of the studied indicator in the group of patients with contrast cholangiography and to decrease in the group of patients without contrast cholangiography was noted. Due to this, in the group of patients without contrast cholangiography after 18 and 42 hours of observation, the activity of serum GGTP becomes statistically significantly lower compared to patients who underwent contrast cholangiography. Also in this group there is a greater degree of reduction of the studied indicator.

In turn, the content of total bilirubin in patients of both observation groups also increased up to $18 \mathrm{~h}$ and then decreased to $42 \mathrm{~h}$, which is statistically significant compared to the previous observation period. However, in patients without contrast cholangiography, the degree of decrease in the studied indicator is greater after 18 and $42 \mathrm{~h}$, which leads to a statistically significant decrease in its absolute values compared with the level at 
hospitalization, as well as compared with the group of patients who underwent cholangiography.

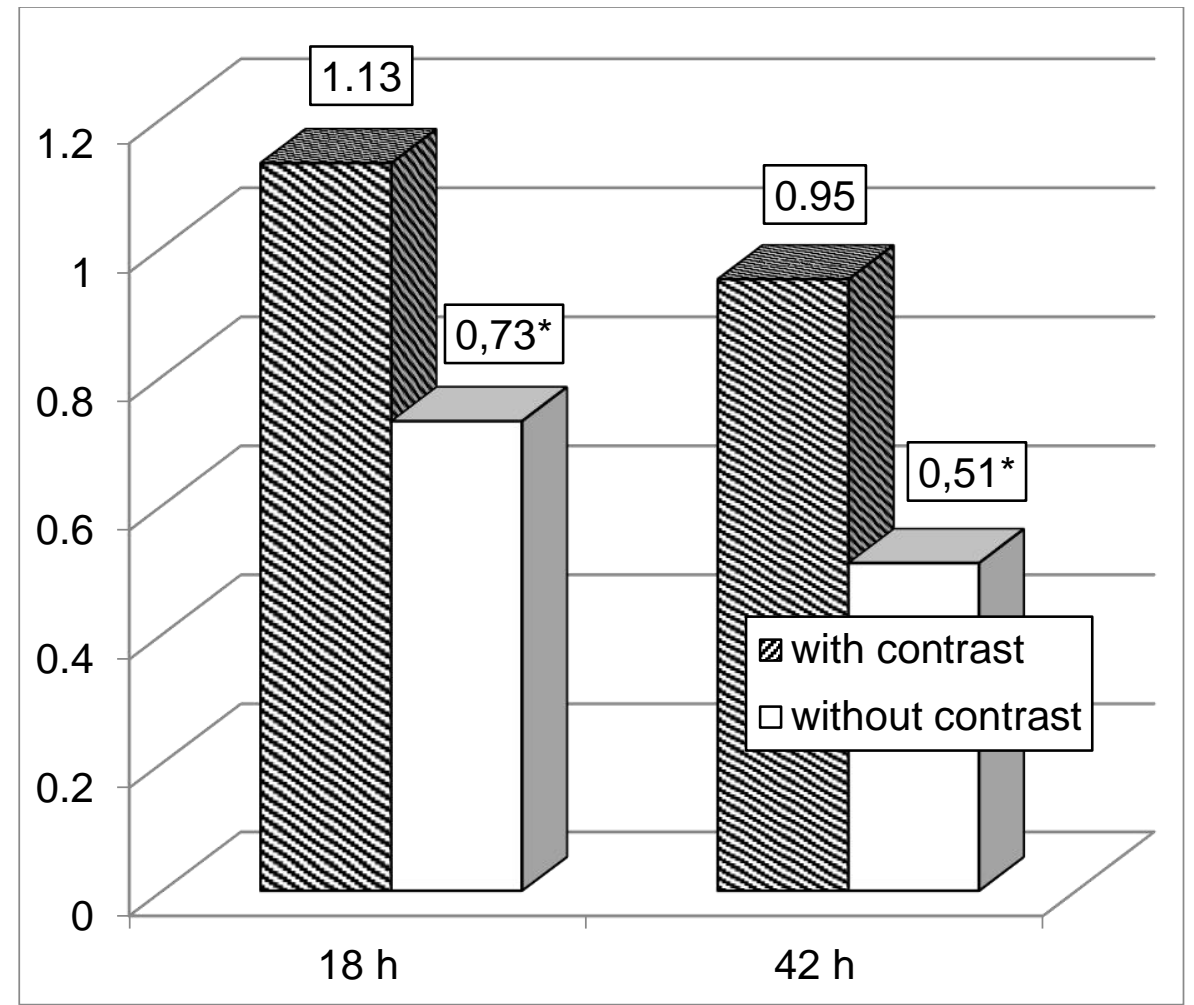

Figure 3 - Dynamics of the average ratio of individual values of total serum bilirubin to the average preoperative period in patients with acute pancreatitis who underwent contrast cholangiography

Dynamics of cytolytic syndrome. Analysis of the dynamics of cytolytic syndrome showed (Table 2) that when hospitalized, the content of L-FABR in the blood serum, the activity of ALT and AST did not differ $(\mathrm{p}>0.05)$ in patients of the comparison groups. However, in the patients who underwent contrast cholangiography, the content of L-FABR compared with the level at hospitalization did not change significantly $(p>0.05)$. There were also no significant differences compared with $18 \mathrm{~h}$ of observation $\left(\mathrm{p}_{2}>0.05\right)$. At the same time, in comparison to the value at the time of hospitalization, the rate of the patients without contrast cholangiography decreased after $18 \mathrm{~h}$ (by 40.69\%, p<0.05) and remained at the same level until $42 \mathrm{~h}\left(\mathrm{p}_{2}>0.05\right)$. Compared with the group of patients who underwent contrast cholangiography, the index after 18 and 42 hours was statistically significantly lower (by 32.5 and $45.4 \%, \mathrm{p}<0.05$, accordingly).

Analysis of the dynamics of the mean ratio of individual values of L-FABR serum to the mean value of the preoperative period (Fig. 4) showed that after 18 and $42 \mathrm{~h}$, the indicator 
in the group of patients without contrast cholangiography was significantly lower than in the comparison group (respectively by 28.7 and $42.1 \%$, p <0.05).

Serum ALT activity in the group of patients with contrast cholangiography did not change during treatment as compared with the level of hospitalization ( $>>0.05)$ and compared with $18 \mathrm{~h}$ of observation $\left(\mathrm{p}_{2}>0.05\right)$. At the same time, in patients without contrast cholangiography, the rate decreased during treatment and after $42 \mathrm{~h}$ became statistically significantly lower than at hospitalization (by $18.8 \%, \mathrm{p}<0.05$ ). Comparison of the examined groups of patients showed that after 18 and $42 \mathrm{~h}$ the activity of ALT in the serum of groups of patients without contrast cholangiography was significantly lower than in the group in which this diagnostic procedure was performed (respectively 22.5 and $32.9 \%, \mathrm{p}_{1}<0.05$ ).

Table 2 - Features of cytolytic syndrome in patients with acute pancreatitis who underwent contrast cholangiography $(\mathrm{M} \pm \mathrm{m})$

\begin{tabular}{|c|c|c|c|}
\hline Period & With contrast $(n=30)$ & $\begin{array}{l}\text { Without contrast } \\
(\mathrm{n}=29)\end{array}$ & $\mathrm{p}_{1}$ \\
\hline \multicolumn{4}{|c|}{$\mathrm{L}-\mathrm{FABR}, \mathrm{nm} \cdot \mathrm{ml}^{-1}$} \\
\hline Before surgery & $280,1 \pm 19,4$ & $364,7 \pm 17,6$ & $>0,05$ \\
\hline $18 \mathrm{~h}$ & $321,1 \pm 19,7$ & $216,8 \pm 15,7^{*}$ & $<0,05$ \\
\hline $42 \mathrm{~h}$ & $319,1 \pm 20,7$ & $174,2 \pm 15,9^{*}$ & $<0,05$ \\
\hline $\mathrm{p}_{2}$ & $>0,05$ & $>0,05$ & \\
\hline \multicolumn{4}{|l|}{ АлАТ, Од•л ${ }^{-1}$} \\
\hline Before surgery & $70,41 \pm 5,63$ & $60,62 \pm 4,14$ & $>0,05$ \\
\hline $18 \mathrm{~h}$ & $72,41 \pm 6,69$ & $56,14 \pm 3,80$ & $<0,05$ \\
\hline $42 \mathrm{~h}$ & $73,34 \pm 5,66$ & $49,21 \pm 2,89^{*}$ & $<0,05$ \\
\hline $\mathrm{p}_{2}$ & $>0,05$ & $>0,05$ & \\
\hline \multicolumn{4}{|l|}{ АсАТ, Од $\cdot^{-1}$} \\
\hline Before surgery & $51,10 \pm 4,19$ & $46,07 \pm 2,10$ & $>0,05$ \\
\hline $18 \mathrm{~h}$ & $51,66 \pm 4,02$ & $40,76 \pm 1,82$ & $<0,05$ \\
\hline $42 \mathrm{~h}$ & $52,55 \pm 4,07$ & $37,62 \pm 1,74^{*}$ & $<0,05$ \\
\hline $\mathrm{p}_{2}$ & $>0,05$ & $>0,05$ & \\
\hline
\end{tabular}

Analysis of the dynamics of the average ratio of individual values of serum ALT activity to the mean value of the preoperative period showed (Fig. 5) that in the group of patients without contrast cholangiography after $42 \mathrm{~h}$ the indicator was significantly lower than in the group of patients where this procedure was performed $(18,3 \%, \mathrm{p}<0.05)$.

The dynamics of AST activity in blood serum was similar in the groups of examined patients (see Table 2). In patients without contrast cholangiography, the value of this indicator 
did not change compared with the level at the time of hospitalization ( $p>0.05)$ and compared with $18 \mathrm{~h}$ of observation $\left(\mathrm{p}_{2}>0.05\right)$.

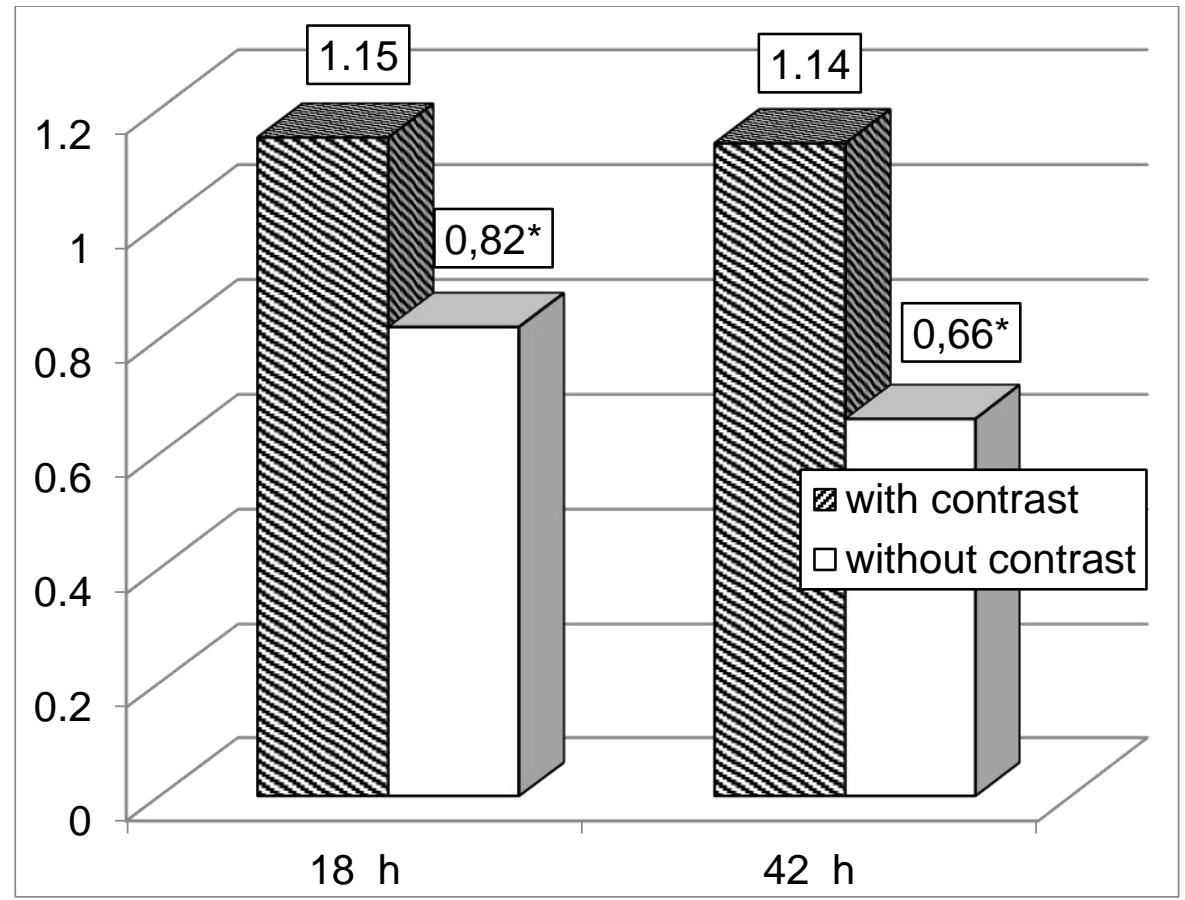

Figure 4 - Dynamics of the mean ratio of individual values of L-FABR serum to the mean value of the preoperative period in patients with acute pancreatitis who underwent contrast cholangiography

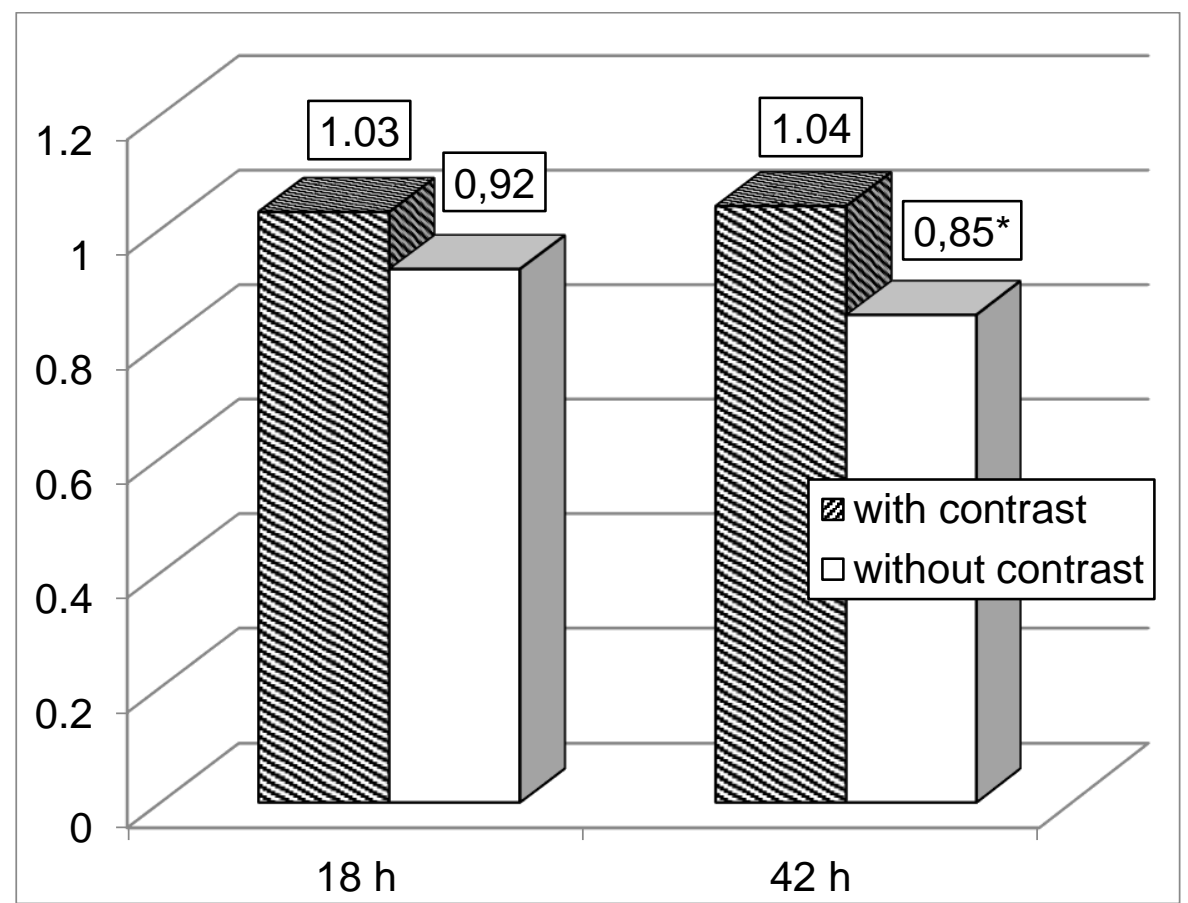

Figure 5 - Dynamics of the average ratio of individual values of serum ALT activity to the average value of the preoperative period in patients with acute pancreatitis who underwent contrast cholangiography 
At the same time, in patients who did not undergo contrast cholangiography, the activity of serum AST was reduced compared to the level at hospitalization. After $42 \mathrm{~h}$, the rate was lower by $18.3 \%$ ( $\mathrm{p}<0.05)$. It is noteworthy that after 18 and 42 hours of examination in the group of patients without contrast cholangiography, the indicator was statistically significantly lower than in the group in which this procedure was performed (accordingly 22.0 and $\left.28.4 \%, \mathrm{p}_{1}<0,05\right)$.

Analysis of the dynamics of the average ratio of individual values of serum AST activity to the average value of the preoperative period (Fig. 6) showed that after $42 \mathrm{~h}$ this indicator in the group of patients without contrast cholangiography was significantly lower $(17.5 \%, \mathrm{p}<0.05)$.

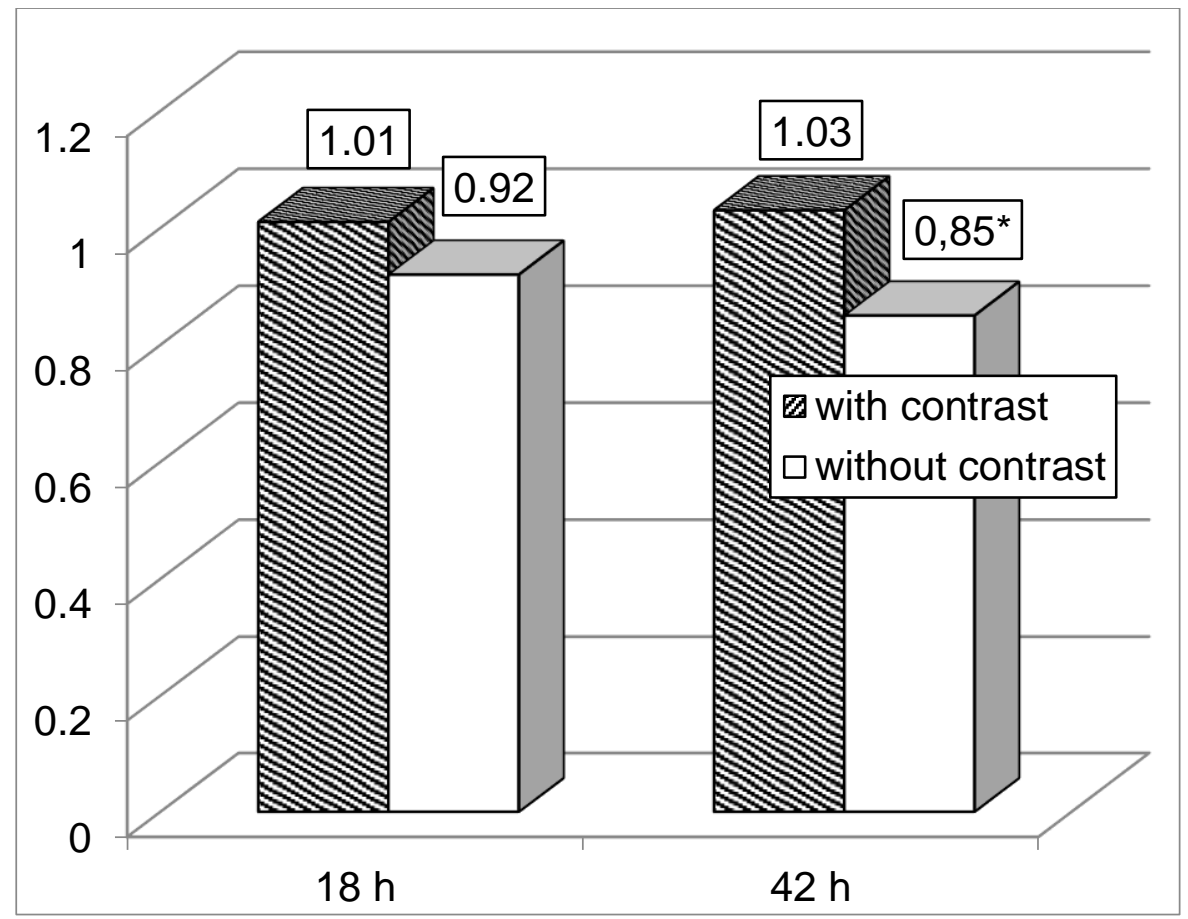

Figure 6 - Dynamics of the average ratio of individual values of serum AST activity to the average value of the preoperative period in patients with acute pancreatitis who underwent contrast cholangiography

Thus, the procedure of contrast cholangiography has a negative effect on the dynamics of cytolytic syndrome in the treatment of patients with acute pancreatitis. Under these conditions, cytolysis markers such as serum L-FABR and ALT and AST activity during treatment are not significantly changed in comparison to the levels at hospitalization. At the same time, in patients who did not undergo contrast cholanigography, the studied indicators reduced and after 42 hours become statistically significantly lower than the ones when hospitalized. At this time, the degree of reduction of the studied indicators also increases 
significantly. This dynamics of cytolysis markers in the group of patients who did not perform contrast cholangiography, leads to significantly lower values of the studied parameters after 18 and 42 hours of observation compared with the group in which contrast cholangiography was performed.

Dynamics of diastasuria. Analysis of the value of diastasuria in patients of the study groups at the hospital admission (Table 3 ) was almost the same ( $>>0.05)$. During treatment in patients who underwent contrast cholangiography, the rate after $18 \mathrm{~h}$ compared to the level at the time of hospitalization increased (by 12.8\%), but the result was not statistically significant. Then up to $42 \mathrm{~h}$ the indicator decreased, which compared to the previous observation period was statistically significant (by $16.1 \%, \mathrm{p}_{2}<0.05$ ).

Table 3 - Dynamics of diastasuria. $\left(\mathrm{g} \cdot \mathrm{l}^{-1} \cdot \mathrm{h}^{-1}\right)$ in patients with acute pancreatitis who underwent contrast cholangiography $(\mathrm{M} \pm \mathrm{m})$

\begin{tabular}{|l|l|l|l|}
\hline Period & With contrast $(\mathrm{n}=30)$ & $\begin{array}{l}\text { Without contrast } \\
(\mathrm{n}=29)\end{array}$ & $\mathrm{p}_{1}$ \\
\hline Before surgery & $1709,5 \pm 101,2$ & $1647,6 \pm 68,9$ & $>0,05$ \\
\hline $18 \mathrm{~h}$ & $1929,1 \pm 108,2$ & $1480,6 \pm 79,5$ & $<0,05$ \\
\hline $42 \mathrm{~h}$ & $1617,6 \pm 111,7$ & $1044,9 \pm 5,94^{*}$ & $<0,05$ \\
\hline $\mathrm{p}_{2}$ & $<0,05$ & $<0,05$ & \\
\hline
\end{tabular}

At the same time, in patients who did not undergo contrast cholangiography, the indicator gradually decreased and after $42 \mathrm{~h}$ became statistically significantly lower than when admitted to the hospital (by $36.5 \%, \mathrm{p}<0.05$ ) and compared with the previous observation period (by $29,4 \%, \mathrm{p}_{2}<0.05$ ). This dynamics led to the fact that in patients without contrast cholangiography, the studied indicator after 18 and $42 \mathrm{~h}$ of treatment was statistically significantly lower than in the comparison group (respectively 23.2 and $35.4 \%, \mathrm{p}<0.05$ ).

Analysis of the dynamics of the average ratio of individual values of diastasuria to the average value of the preoperative period (Fig. 7) showed that after $18 \mathrm{~h}$ and $42 \mathrm{~h}$ the study in the group of patients without contrast cholangiography was statistically significantly lower than in the group in which this procedure was performed (respectively 15.0 and $28.4 \%, \mathrm{p}$ $<0.05)$.

Thus, the value of diastasuria in the group of patients with contrast cholangiography after $18 \mathrm{~h}$ of treatment increases compared to the level at the time of hospitalization. Although the differences are not significant, in the future the indicator decreases and becomes statistically significant compared to the previous observation period. In the group of patients 
without contrast cholangiography, the indicator decreases during treatment and after 42 hours becomes lower compared to the level at the time of hospitalization and the previous observation. After 18 and 42 hours in this group, the absolute value of the indicator is significantly smaller than in the comparison group, and the degree of decrease, on the contrary is significantly higher.

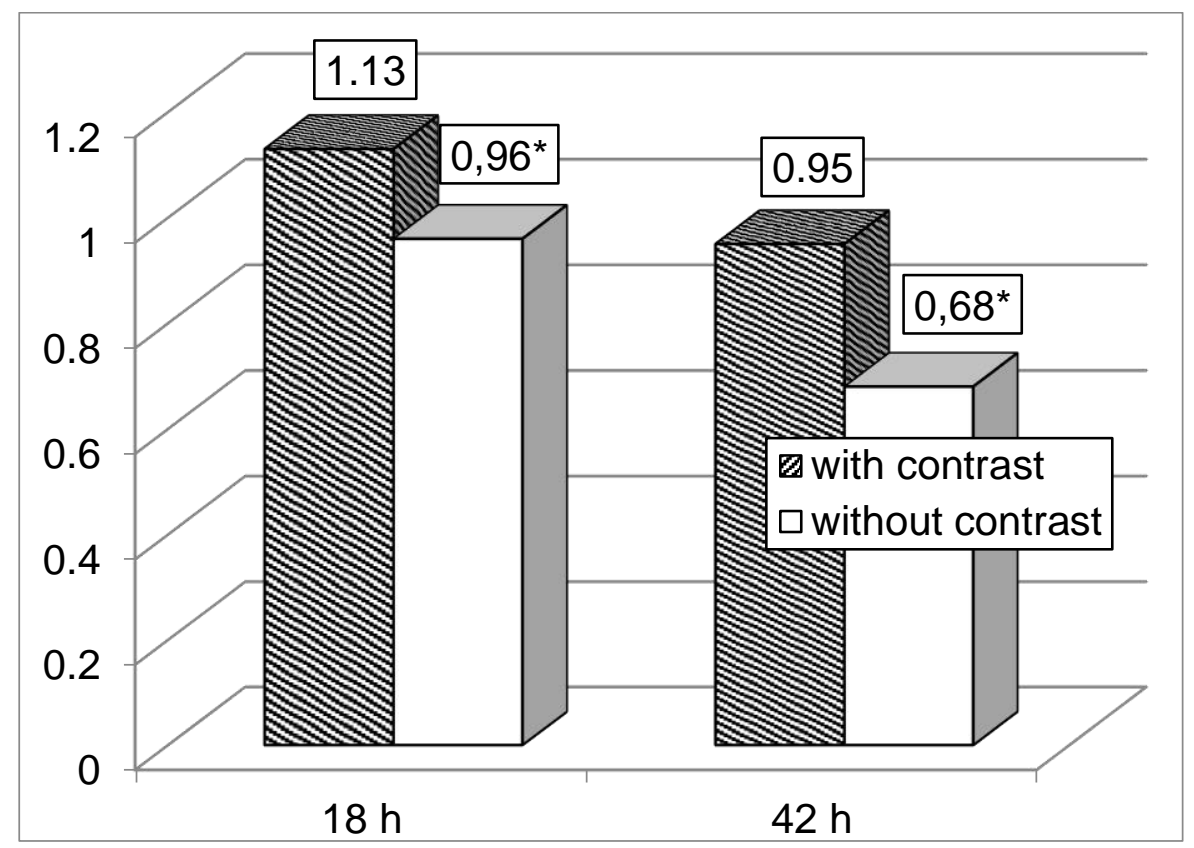

Figure 7 - Dynamics of the average ratio of individual values of diastasuria to the average value of the preoperative period in patients with acute pancreatitis who underwent contrast cholangiography

Conclusions and prospects of further developments. 1. Regardless of the performance of contrast cholangiography, in the postoperative period the activity of GGTP in the serum was not significantly changed in comparison to the one at the time of hospitalization. The tendency to the increase of the value of the studied indicator in the group of patients with contrast cholangiography and to the decrease of the one in the group of patients without contrast cholangiography was noted. Due to this, in the group of patients without contrast cholangiography after 18 and 42 hours of observation, the activity of serum GGTP became statistically significantly lower compared to patients who underwent contrast cholangiography. Also in this group there is a greater degree of reduction of the studied indicator.

2. The content of total bilirubin in patients of both groups of observation also increases up to $18 \mathrm{~h}$ and then decreases to $42 \mathrm{~h}$, which is statistically significant compared to the previous observation period. In patients without contrast cholangiography, the degree of 
decrease in the studied indicator is higher after 18 and $42 \mathrm{~h}$, which leads to a statistically significant decrease in its absolute values compared with the level at hospitalization, as well as compared with the group of patients who underwent cholangiography.

3. Contrast cholangiography has a negative effect on the dynamics of cytolytic syndrome during treatment of patients with acute pancreatitis. Under these conditions, cytolysis markers such as serum L-FABR and ALT and AST activity during treatment are almost unchanged compared to the hospitalization levels. At the same time, in patients who did not undergo contrast cholanigography, the studied indicators reduced and after 42 hours become statistically significantly lower than when hospitalized. During this period, the degree of reduction of the studied indicators also significantly decreases. This dynamics of cytolysis markers in the group of patients who did not undergo contrast cholangiography, leads to significantly lower values of the studied parameters after 18 and 42 hours of observation compared with the group in which contrast cholangiography was performed.

4. The value of diastasuria in the group of patients with contrast cholangiography after 18 hours of treatment increases compared to the level at the time of hospitalization. Although the differences are not significant, in the future the indicator decreases and becomes statistically significant compared to the previous observation period. In the group of patients without contrast cholangiography, the rate decreases during treatment and after 42 hours becomes lower compared to the level at the time of hospitalization and the previous observation. After 18 and 42 hours in this group, the absolute value of the indicator is significantly lower than the one in the comparison group, and the degree of decrease, on the contrary is higher.

\section{References}

1. Tenner C, Bailey J, DeWitt J, Vege SS. Guide to the American College of Gastroenterology: treatment of acute pancreatitis // Am J Gastroenterol. 2013; 108: P. 1400$115 ; 1416$

2. Alper E., Arabul M., Aslan F., Cekic C., Celik M., Ipek S., Unsal B. Radial EUS Examination Can be Helpful in Predicting the Severity of Acute Biliary Pancreatitis // Medicine (Baltimore). - 2016. - Jan., 95 (3). - P. 2321.

3. Jaipuria J., Bhandari V., Chawla A., Singh M. Intra-abdominal pressure: Time ripe to revise management guidelines of acute pancreatitis? // World J.Gastrointest. Pathophysiol. - 2016 - Feb. 15., 7 (1). - P. 186-198. 
4. Kondratenko PG, Konkova MV, Dzhansyz IN Minimally invasive interventions in the surgical treatment of patients with acute nonbiliary aseptic necrotic pancreatitis // Modern medical technologies. - 2011. - № 3-4. - P. 161-164.

5. Dronyak MM Differentiated surgical tactics in patients with acute biliary pancreatitis and jaundice syndrome / MM Dronyak // Clinical surgery. - 2005. - №1 . - P. 3234.

6. Zvyagintseva TD, Shargorod II Chronic pancreatitis: modern concepts of pathogenesis, diagnosis and treatment // Eastern European Journal of Internal and Family Medicine. - 2015. - №2. - P.10-16.

7. Kondratenko PG Acute pancreatitis: conceptual issues of diagnosis and treatment tactics / P.G. Кондратенко, M.B. Konkova // Ukrainian Journal of Surgery. - 2009. - №1. - P. 68-76.

8. Kharchenko NV Modern trends in the treatment of diseases of the pancreas with exocrine insufficiency // Health of Ukraine. —№ 19 (272). - 2014. - P. 32-39.

9. Gubergritz N.B. Fomenko PG, Belyaeva NV "Fatal chain": in pancreatology too // Modern gastroenterology -№5 (91). - 2018. - P. 97-102.

10. Mulder CJ, Bruno MJ. Lack of a single opinion on the role of endoscopic retrograde cholangiography in acute biliary pancreatitis in published meta-analyzes and guidelines // Systematic Review. - 2013; Vol. 42: P. 774-780.

11. Stevens T. Endoscopic ultrasound for the diagnosis of chronic pancreatitis / T. Stevens, M.A. Parsi // World J. Gastroenterol. - 2013. - Vol.16, №23. - P. 2841-2850.

12. Diagnostics and treatment of acute biliary pancreatitis / S.G. Shapovalyants, A.G. Mylnikov, S.Yu. Orlov [et al.] // Annals of Surgical Hepatology. - 2009. - T. 14. - No. 1. - P. 29-33.

13. Kolosovich IV Acute biliary pancreatitis: modern problems of diagnosis and treatment / I.V. Kolosovich, R.Yu. Spitsyn // Surgery of Ukraine. - 2006. - № 4. - P. 53-56.

14. Management of the critically ill patients with severe acute pancreatitis / A. Nathens, R. Curtis, R. Beale [at al.]. // Crit Care Med. - 2004. - Vol. 32. № 12. P. 25242536.

15. Complex treatment of acute biliary pancreatitis, combined with acute calculous cholecystitis, using modern endosurgical methods / E.D. Hvorostov, Yu.B. Zakharchenko, MS Tomin [etc.] // Ukrainian Journal of Surgery. - 2011. - № 6. - P. 43-46. 